\title{
Inflammatory profiling of patients with familial amyloid polyneuropathy
}

\author{
Estefania P. Azevedo ${ }^{1}$, Anderson B. Guimaraes-Costa ${ }^{2}$, Christianne Bandeira-Melo ${ }^{3}$, Leila Chimelli ${ }^{4}$, \\ Marcia Waddington-Cruz ${ }^{5}$, Elvira M. Saraiva ${ }^{2}$, Fernando L. Palhano ${ }^{1}$ and Debora Foguel ${ }^{1 *}$ (D)
}

\begin{abstract}
Background: Familial amyloid polyneuropathy (FAP) or ATTRv (amyloid TTR variant) amyloidosis is a fatal hereditary disease characterized by the deposition of amyloid fibrils composed of transthyretin (TTR). The current diagnosis of ATTRv relies on genetic identification of TTR mutations and on Congo Red-positive amyloid deposits, which are absent in most ATTRv patients that are asymptomatic or early symptomatic, supporting the need for novel biomarkers to identify patients in earlier disease phases allowing disease control.

Methods: In an effort to search for new markers for ATTRv, our group searched for nine inflammation markers in ATTRv serum from a cohort of 28 Brazilian ATTRv patients.

Results: We found that the levels of six markers were increased (TNF-a, IL-1 $\beta, I L-8, I L-33$, IFN- $\beta$ and IL-10), one had decreased levels (IL-12) and two of them were unchanged (IL-6 and cortisol). Interestingly, asymptomatic patients already presented high levels of IL-33, IL-1 $\beta$ and IL-10, suggesting that inflammation may take place before fibril deposition.

Conclusions: Our findings shed light on a new, previously unidentified aspect of ATRR, which might help define new criteria for disease management, as well as provide additional understanding of ATTRV aggressiveness.
\end{abstract}

Keywords: Amyloid, Transthyretin, Biomarkers, Cytokines, Familial amyloid polyneuropathy

\section{Background}

Familial amyloid polyneuropathy (FAP) or ATTRv (amyloid TTR variant) amyloidosis is an autosomal dominant hereditary disease characterized by the accumulation of amyloid fibrils in peripheral nerves, the gastrointestinal tract and the heart $[1,2]$. Disease onset is intimately associated with mutations in the TTR gene, located in the chromosome 18 , which gives rise to a $55 \mathrm{kDa}$ plasmatic protein named transthyretin [1]. Transthyretin (TTR) is a tetrameric protein expressed and secreted mainly by the liver, but also by the choroid plexus epithelia in the brain [1]. Once in the plasma or in the cerebrospinal fluid, TTR acts as a retinol-binding protein and thyroxine transporter across the body and the brain [1]. More than 100-point mutations in the TTR gene have been described worldwide and most of them culminate in the

\footnotetext{
* Correspondence: foguel@biogmed.ufrj.br

${ }^{1}$ Instituto de Bioquímica Medica Leopoldo de Meis, Universidade Federal do Rio de Janeiro, Rio de Janeiro, Brazil

Full list of author information is available at the end of the article
}

production of dysfunctional TTR with a high thermodynamic instability compared to the wild-type protein $[3,4]$. Only a handful of mutations are not pathogenic, such as the T119 M mutation [3, 5]. Most TTR mutations have a high propensity to aggregate under denaturing and even physiological conditions [6], forming amyloid fibrils that deposit in various tissues and organs, causing organ dysfunction [1]. The Val30Met (V30 M) variant is the most common mutation affecting a large population of people worldwide [1, 7]. In particular, a recent study [8] suggested an importance of late-onset cases of V30 M amyloidosis in addition to conventional early-onset studies cases.

The diagnosis of ATTRv is challenging, often relying on genetic tools to identify TTR mutations as well as on the identification of Congo Red-positive amyloid deposits in biopsies usually taken from sural nerve and salivary glands [7, 9]. ATTRv patients have been treated by liver transplantation (LT), since the liver is the major organ of TTR production. Unfortunately, LT presents 
mortality risks and it is not available to all patients [9]. More recently, a new drug (Tafamidis) that works by stabilizing the TTR protein is available in several countries showing effective results in controlling disease progression [10], but this drug is only available for patients that fulfill certain criteria, such as presenting an amyloidpositive biopsy. However, the amount of ATTRv patients that present ATTRv symptoms without having positive biopsies is significant $[11,12]$, reinforcing the need for new criteria and novel biomarkers to choose patients that should receive immediate treatment.

Most physicians and pathologists have regarded ATTRv as a disease without an inflammatory component, since most biopsies and ex vivo analysis showed no leukocyte infiltration [13]. Nevertheless, the presence of proinflammatory markers such as TNF- $\alpha$ and IL- $1 \beta$ has been described in biopsies of ATTRv patients [13, 14]. Interestingly, the levels of proinflammatory and oxidative markers in ex vivo tissue positively correlate with the scoring stage proposed by Coutinho and colleagues in ATTRv patients, which is an index used to discriminate disease progression [15]. In addition, an animal model of ATTRv showed increased levels of inflammation-related transcripts in both liver and heart, suggesting that inflammation might play an important role in ATTRv progression [16].

Although, these data indicate a possibility that inflammation may play a role in ATTRv pathogenesis, there are no data available showing which specific inflammatory components are altered in humans. Herein, we searched for inflammation markers in serum collected from a cohort of 28 ATTRv patients in comparison to age and sex-matched controls. We found alterations in six out of nine cytokine levels (TNF- $\alpha$, IL-1 $\beta$, IL-8, IL33 , IFN- $\beta$, IL-10 and IL-12) compared to healthy agematched subjects. Interestingly, asymptomatic patients (FAP 0) already presented high levels of some cytokines, suggesting that inflammation may take place before fibril deposition. Notably, in the case of TNF- $\alpha$, cytokine levels positively correlated with disease progression, indicating a deeper involvement of this cytokine in ATTRv pathogenesis. Our findings shed light to a new, previously unidentified aspect of ATTRv, which might help understanding the aggressiveness of disease and vulnerability of affected individuals.

\section{Methods}

\section{Human serum}

Serum from 28 patients genetically and clinically diagnosed with ATTRv (17 males and 11 females; male/female ratio 1.5:1) were collected from the University Hospital Clementino Fraga Filho of the Federal University of Rio de Janeiro (HUCFF). Serum was collected using standard hospital procedures. Briefly, Vacutainer ${ }^{\circ}$ tubes were used to collect 5-10 $\mathrm{mL}$ of blood. Samples were centrifuged after clotting and readily frozen at $-80^{\circ} \mathrm{C}$. All patients carried the Val30Met mutation. Additionally, serum from 24 healthy donors with a similar female/male ratio was collected and used as control (HS; healthy subjects). We have classified the asymptomatic patients (or asymptomatic carriers) as those patients diagnosed with ATTRv by means of genetic screening, but that do not present ATTRv symptoms yet. This study was approved by the National Committee in Research Ethics (CONEP; CAAE \#03102012.4.1001.5257) and informed consent was obtained from all donors. For some of the cytokines measured, the amount of sera available was below the amount necessary for measurement and thus, was excluded from analysis.

\section{Cytokine quantification}

Cytokines were analyzed in whole serum using enzymelinked immunosorbent assays (ELISA) and commercially available kits: IL-8, IL-33, IL-10, IL-6, IL-12, TNF- $\alpha$ (Peprotech), IL-1 $\beta$ (Invitrogen) and IFN- $\beta$ and Cortisol (Lifetech Biotechnologies) following the specific manufacturer's instructions.

\section{Statistical analysis}

All statistical analysis was performed using nonparametric two-tailed Student's t-test and post-hoc Mann-Whitney test or one-way ANOVA followed by post-hoc Tukey or Kruskal-Wallis test.

\section{Results}

In this study, we included a total of 28 patients previously diagnosed with ATTRv and scored with the scoring system by Coutinho [15] to evaluate disease progression (termed herein FAP $0=$ asymptomatic; FAP 1 = unimpaired ambulation; mostly mild sensory, motor, and autonomic neuropathy in the lower limbs; FAP $2=$ assistance with ambulation required; mostly moderate impairment progression to the lower limbs, upper limbs, and trunk; FAP 3 = wheelchair-bound or bedridden; severe sensory, motor, and autonomic involvement of all limbs). Twenty-five of them were considered early onset $(<50$ years old) and three were considered late-onset (> 50 years old). To better analyze the parameters chosen, the groups were matched to the control group (healthy subjects; HS) and no significant differences in terms of age were observed $(p>0.05$, One-way ANOVA with Tukey correction, Table 1). In all patients, the diagnosis was confirmed by histopathology of biopsied material, clinical criteria and genetic sequencing of the TTR gene being all patients V30 M [7]. With the exception of FAP 0 , among our groups of patients, the ratio between male: female had prevalence for males, as noticed in other studies (Table 1) [17]. The patient means ages in FAP 0, 
Table 1 Patient's Characteristics

\begin{tabular}{lllll}
\hline & Healthy Subjects $(\mathrm{HS})$ & FAP 0 & FAP 1 & FAP 2-3 \\
\hline Number of subjects & 24 & 6 & 16 & 6 \\
Male: Female Ratio & $2: 1$ & $1: 5$ & $2.2: 1$ & $5: 1$ \\
Mean age (range) & $36.5(25-61)$ & $27.5(24-31)$ & $38.1(26-71)$ & $35.4(24-58)$
\end{tabular}

1 and $2-3$ sub-groups was $27.5,38.1$ and 35.4 , respectively (Table 1).

\section{Comparing the levels of pro- and anti-inflammatory cytokines, interferon- $\beta$ and cortisol between healthy} subjects (HS) and ATTRv patients

Although previous studies have reported elevated levels of pro-inflammatory molecules such as TNF- $\alpha$ and IL$1 \beta$ in biopsies from ATTRv patients [13, 14, 18], we asked here whether these pro-inflammatory cytokines were also increased in serum of ATTRv patients and whether this increase has any correlation with disease progression. We also assessed five additional cytokines, IL-8, IL-33, IL-10 and IFN- $\beta$. Both IL-8 and IL-33 have been associated with promoting inflammation and inducing the recruitment of neutrophils to tissues [19, 20]. Neutrophils are innate immune cells known to be activated by amyloid fibrils in vitro and in vivo [21]. The anti-inflammatory cytokine IL-10 can modulate negatively pro-inflammatory cytokine production by phagocytes and other cells, thus decreasing excessive inflammation [22]. We also evaluated the level of IFN- $\beta$ in our samples, which is a type I interferon molecule that can modulate microbial and autoimmune responses [23, 24]. In Fig. 1, where all ATTRv patients were grouped together, we observed that ATTRv patients had increased levels of IL-8 (Fig. 1a; $135.5 \pm 25.21 \mathrm{pg} / \mathrm{mL}$ compared to $65.97 \pm 25.14$ $\mathrm{pg} / \mathrm{mL}$ in HS), IL-33 (Fig. 1b; $748.2 \pm 195.5 \mathrm{pg} / \mathrm{mL}$ compared to $252.1 \pm 94.32 \mathrm{pg} / \mathrm{mL}$ in HS), IL-1 $\beta$ (Fig. 1c; $15.13 \pm 4.659 \mathrm{pg} / \mathrm{mL}$ compared to $0.8417 \pm 0.5678 \mathrm{pg} / \mathrm{mL}$ in HS), TNF- $\alpha$ (Fig. $1 \mathrm{~d} ; 342.6 \pm 26.09 \mathrm{pg} / \mathrm{mL}$ compared to $164.4 \pm 8.067 \mathrm{pg} / \mathrm{mL}$ in HS), IL-10 (Fig. 1e; $7.609 \pm 0.2177$ $\mathrm{ng} / \mathrm{mL}$ compared to $3.970 \pm 0.1362 \mathrm{ng} / \mathrm{mL}$ in HS), IFN- $\beta$ (Fig. 1g; $5.770 \pm 1.367 \mathrm{IU} / \mathrm{mL}$ compared to $0.8739 \pm$

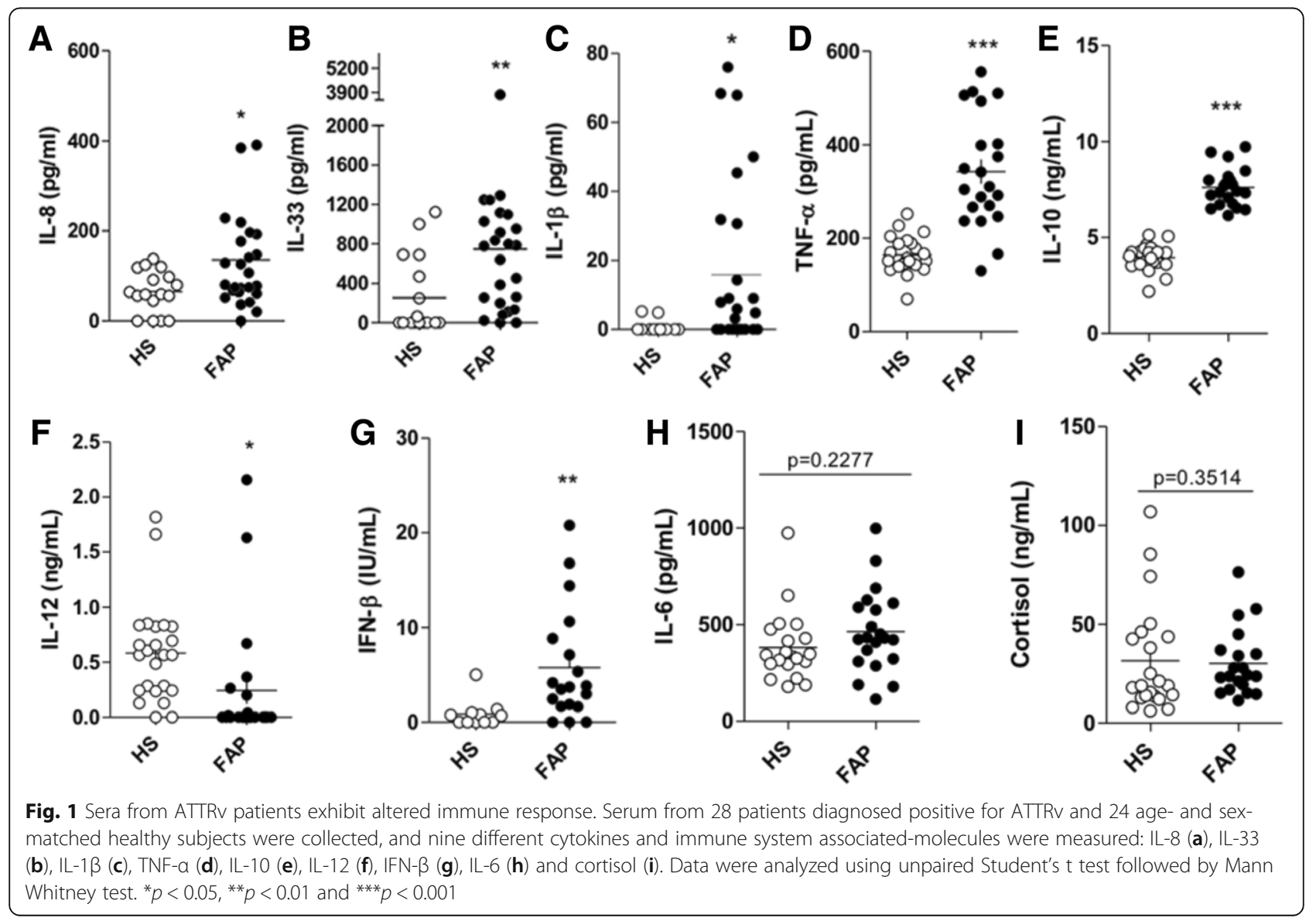


$0.4395 \mathrm{IU} / \mathrm{mL}$ in $\mathrm{HS})$. We also evaluated the levels of IL12 , which is mainly produced by phagocytes and can increase the production of IL-8 in neutrophils [25]. Interestingly, we observed a decrease in IL-12 levels (Fig. 1f; $0.2425 \pm 0.1203 \mathrm{ng} / \mathrm{mL}$ compared to $0.5825 \pm 0.09183 \mathrm{ng} /$ $\mathrm{mL}$ in $\mathrm{HS}$ ). We also evaluated IL-6, a cytokine that has dual anti- and pro-inflammatory effects in many different tissues [26], and cortisol, a glucocorticoid that can modulate energy metabolism and suppress immune responses [27] in the serum of ATTRv patients compared to healthy subjects. The levels of both molecules were unchanged when compared to healthy subjects (Fig. 1h, i).

\section{Asymptomatic patients (FAP 0) already exhibit altered levels of pro- and anti-inflammatory cytokines}

To evaluate whether the levels of the cytokines here investigated change with disease progression, we plotted their levels in FAP 0,1 and $2-3$ patients and compared to the HS (Fig. 2). We observed that FAP 0 patients already exhibited a significant increase in levels of IL-33, IL-1 $\beta$ and IL-10 (Fig. $2 b, c$ and e), suggesting that the alterations in immune response might occur before amyloid deposition and symptom appearance. In the case of IL-10, the increment already observed in FAP 0 persists with disease progression with no further alteration in other disease stages (Fig. 2e). In the case of IL-33, a similar scenario was observed with the exception that in FAP 2-3 patients this cytokine decreased, presenting similar values as the HS (Fig. 2b). Notably, we found that the levels of TNF- $\alpha$ increased progressively with disease progression, and was significantly different from the HS (Fig. 2d). For all the other cytokines, namely IL-8, IL-12, IL-6, IFN- $\beta$ and cortisol, their levels did not change and were not significantly different from the HS (Fig. 2a, f-i).

In summary, we presented here a panel of several cytokines from 28 ATTRv patients demonstrating the presence of altered pro- and anti-cytokine levels in serum. These data provide new knowledge regarding ATTRv pathogenesis, suggesting that a relevant immune component exists in ATTRv which opens the possibility for new biomarkers for disease diagnostics (Table 2).

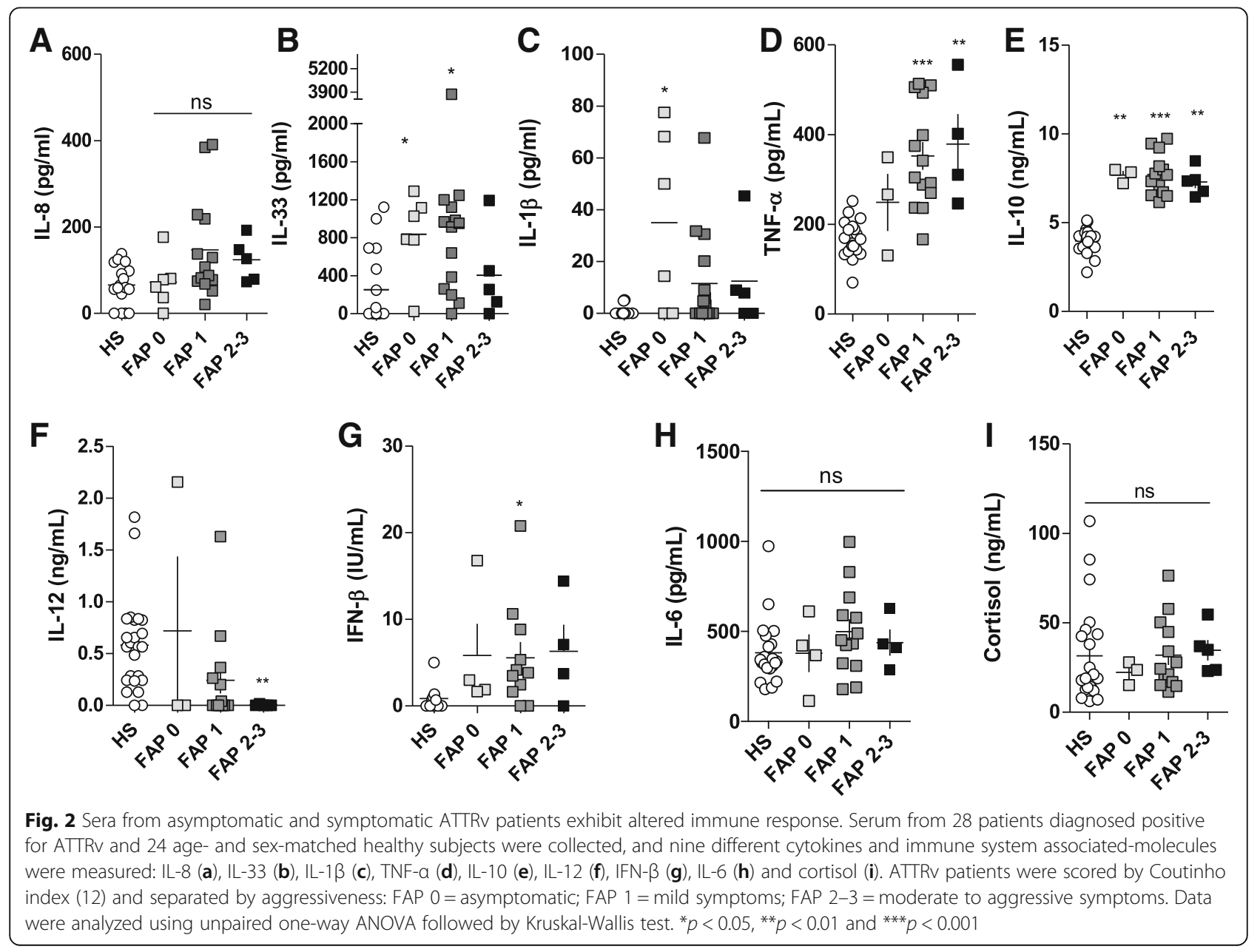


Table 2 Summary of cytokines levels in FAP disease stages compared to healthy subjects

\begin{tabular}{llllllllll}
\hline & $\mathrm{IL}-8$ & $\mathrm{IL}-6$ & $\mathrm{IL}-33$ & $\mathrm{IL}-10$ & $\mathrm{IL}-1 \beta$ & TNF-a & IFN- $\beta$ & IL-12 & Cortisol \\
\hline FAP 0 & unchanged & unchanged & $\uparrow$ & $\uparrow$ & $\uparrow$ & unchanged & unchanged & unchanged & unchanged \\
FAP 1 & unchanged & unchanged & $\uparrow$ & $\uparrow$ & unchanged & $\uparrow$ & $\uparrow$ & unchanged & unchanged \\
FAP 2-3 & unchanged & unchanged & unchanged & $\uparrow$ & unchanged & $\uparrow$ & unchanged & $\downarrow$ & unchanged \\
\hline
\end{tabular}

\section{Conclusions}

The most common mutation leading to ATTRv is V30 $\mathrm{M}$, causing TTR to aggregate forming amyloid fibrils [7]. The majority of patients present polyneuropathy and other complications such as diarrhea/constipation, and sexual impotence among others [1, 7]. However, the mechanism leading to these disorders are unknown. The presence of extracellular deposits of amyloid fibrils composed of wild-type or mutated TTR is shared by all patients [1], but whether these deposits are responsible for disease symptoms is still unclear. For many decades, ATTRv was thought to be a disease in which inflammation was not present [13], due to the lack of leukocyte infiltration observed in ex vivo tissues [13].

Several studies have described the presence of inflammatory markers in ex vivo biopsies [13, 14, 18], suggesting that nerves and surrounding tissue might produce pro- and anti-inflammatory molecules as a stress response or to modulate disease progression. However, no change in leukocyte markers was found, suggesting that the sural nerve or peripheral tissue might be the source of such inflammation [13]. Although the source of the serum TNF- $\alpha$ described by our group is unknown, we cannot discard that inflammatory cells recruited to the sural nerve in response to TTR deposits might be responsible for its production. Another possibility is the expression of TNF- $\alpha$ by Schwann cells present in the sural nerve [28]. Moreover, it is yet unknown whether the inflammatory cytokines detected in this study are primarily related to the pathogenesis or a secondary effect of tissue damage. In addition, many ATTRv patients report neuropathic pain [29], which may modify cytokine profiles [30].

Here, we measured in serum of 28 ATTRv patients the levels of 9 different inflammation-associated molecules and described that ATTRv patients have altered levels of these cytokines, some of them involved in pro- and antiinflammatory response. In addition, asymptomatic patients already have altered levels of IL-33, IL-1 $\beta$ and IL10 levels. These altered immune responses observed in asymptomatic patients are a novel finding and suggest that the body is reacting to the disease before any amyloid deposition or tissue degeneration occurs. We couldn't test sex-specific differences in our cohort due to the small number of male and female patients. However, Kurian and colleagues have observed sex-specific changes in blood cells gene expression from ATTRv patients, suggesting that inflammatory gene markers in circulating blood cells might be influenced by sexual dimorphisms [31]. Curiously, in their study, a correlation of upregulated immune/inflammatory genes was observed among symptomatic versus asymptomatic males, but not in in females [31]. One important limitation to this study is the difficulty to recruit patients in Brazil for serology studies, thus it remains unknown whether these cytokine changes in serum would also be present in patients with a different TTR mutation and a non-TTR neuropathy (Chronic inflammatory demyelinating polyneuropathy; CIDP).

One possibility is that the synthesis and folding process of the mutated and unstable TTR in the liver requires more energy and thus, may cause endoplasmic reticulum (ER) stress and the activation of the liver unfolding protein response (UPR). ER stress and the activation of UPR in liver were shown to cause proinflammatory cytokines production [32,33], which could fuel inflammation by further activating liver macrophages (Kupffer cells) as seen in other non-amyloid disease $[34,35]$. In a recent publication by Kurian and collaborators, it was shown that genes related to eIF2 pathway were downregulated in all ATTRv patients in relation to the asymptomatic ones. This pathway is one arm of the protein unfolding response and its activation could be related to initiation of the proinflammatory response in ATTRV patients described here [31]. Interestingly, Buxbaum and colleagues showed in a mouse model of ATTRv that liver from mice that presented no amyloid deposits exhibited altered expression of diverse transcripts associated with innate immunity and inflammation [16]. Our data and the one from that study suggest that before amyloid deposition occurs, gene expression and protein levels of inflammatory markers are altered in mice [16] and humans with ATTRv. It remains unknown whether this might be a way to modulate disease progression or is merely a consequence of misfolded TTR local synthesis. A better understanding of why these alterations occur in serum and whether the liver plays an important role in this phenomenon may provide new insights to improve the quality of life of patients that also undergo domino liver transplant. In this procedure, a liver failure patient receives a liver from an ATTRv patient. However, a five-year study described that $35 \%$ of patients that underwent domino liver transplantation presented ATTRv amyloidosis earlier than 
donor ATTRv patients [36]. These data indicate that ATTRv patients may have altered liver capacity, putting domino liver recipients at risk.

Another possibility is that the inflammatory response is a reaction to circulating small oligomers. Amyloid oligomers are formed before fibril deposition, are toxic to cells [37], and elicit inflammation when presented to immune cells [21]. Small, toxic oligomers can also be produced in situ after the cleavage of mature fibrils through the action of local proteases [21].

Altered immune response and inflammation can affect a myriad of pathways including glucose [38], and lipid metabolisms [39], among others. The patients with ATTRv also present gastrointestinal symptoms, cachexia, malnutrition, diarrhea and others [1,7]. Cytokines such as IL-1 $\beta$ are important players in inflammation-induced anorexia and weight loss, due to its action in the hypothalamus-pituitary-adrenal axis (HPA) [40]. One hypothesis is that altered IL- $1 \beta$ levels might change neuroendocrine pathways leading to anorexia and thus, cachexia in ATTRv patients. IL-1 $\beta$ also is known as a modulator of other pro-inflammatory cytokines [41] that might also influence neuroendocrine metabolism. Interestingly, in some patients, cachexia is not correlated with dysautonomia and malabsorption.

The novel observation of alterations in immune response in serum from ATTRv patients suggests an important role of inflammation in ATTRv pathogenesis. This new focus on inflammation in ATTRv pathogenesis and progression provides new directions towards understanding this fatal disease and improving clinical criteria for choosing ATTRv patients that should receive Tafamidis treatment. The drug has already showed positive results in clinical trials [10], but due to current clinical criteria is being administered to ATTRv patients that are already debilitated by disease. If these inflammatory markers could be evaluated in other ATTRv populations showing a similar profile with disease progression, we envision the possibility of using them as ATTRv biomarkers, which could be assessed vary rapidly and very easily.

\section{Additional file}

Additional file 1: Raw Data from Patients. (XLSX $12 \mathrm{~kb}$ )

\begin{abstract}
Abbreviations
ATTRv: Amyloid transthyretin variant; FAP: Familial amyloidotic polyneuropathy; HS: Healthy subjects; LT: Liver transplantation; UPR: Unfolding protein response
\end{abstract}

\section{Acknowledgements}

We thank Mr. Santiago Alonso and Mr. Emerson Gonçalves with the lab technical assistance.

\section{Authors' contributions}

EPA and ABG-C - acquisition and analysis of the data; writing of the manuscritpt. CB-M, LC, EMS - conception and designed the work; interpretation of the data. MW-C, FLP and DF- designed the work; interpretation of the data; write the paper. All authors have approved the submitted and revised version of the manuscript.

\section{Funding}

We also thank the funding agencies Fundação Carlos Chagas Filho de Amparo à Pesquisa do Estado do Rio de Janeiro (FAPERJ), Coordenação de Aperfeiçoamento de Pessoal de Nível Superior (CAPES), Conselho Nacional de Desenvolvimento Científico e Tecnológico (CNPq). Funding Agencies had no role in the design of the study; collection, analysis, and interpretation of data; and in writing the manuscript.

\section{Availability of data and materials}

Raw data were submitted as Additional file 1.

\section{Ethics approval and consent to participate}

This study was approved by the National Committee in Research Ethics (CONEP; CAAE \#03102012.4.1001.5257) and written informed consent was obtained from all donors.

\section{Consent for publication}

Not applicable

\section{Competing interests}

The authors declare that they have no competing interests.

\section{Author details}

'Instituto de Bioquímica Medica Leopoldo de Meis, Universidade Federal do Rio de Janeiro, Rio de Janeiro, Brazil. ${ }^{2}$ Instituto de Microbiologia Paulo de Goes, Universidade Federal do Rio de Janeiro, Rio de Janeiro, Brazil. ${ }^{3}$ Instituto de Biofísica Carlos Chagas Filho, Universidade Federal do Rio de Janeiro, Rio de Janeiro, Brazil. " Serviço de Anatomia Patológica do Hospital Universitário Clementino Fraga Filho, Universidade Federal do Rio de Janeiro, Rio de Janeiro, Brazil. ${ }^{5}$ Serviço de Neurologia do Hospital Universitário Clementino Fraga Filho, Universidade Federal do Rio de Janeiro, Rio de Janeiro, Brazil.

Received: 3 December 2018 Accepted: 18 June 2019

Published online: 28 June 2019

\section{References}

1. Planté-Bordeneuve V, Said G. Familial amyloid polyneuropathy. Lancet Neurol. 2011;10:1086-97.

2. Hund E. Familial amyloidotic polyneuropathy: current and emerging treatment options for transthyretin-mediated amyloidosis. Appl Clin Genet. 2012:18:37-41.

3. Sekijima Y, Wiseman RL, Matteson J, Hammarstrom P, Miller SR, Sawkar AR, Balch WE, Kelly JW. The biological and chemical basis for tissue-selective amyloid disease. Cell. 2005;121:73-85.

4. Gertz MA, Benson MD, Dyck PJ, Grogan M, Coelho T, Cruz M, Berk JL, Plante-Bordeneuve V, Schmidt HHJ, Merlini G. Diagnosis, prognosis, and therapy of transthyretin amyloidosis. J Am Coll Cardiol. 2015;66:2451-66.

5. Coelho T, Carvalho M, Saraiva MJ, Alves I, Almeida MR, Costa PP. A strikingly benign evolution of ATTRV in an individual found to be a compound heterozygote for two TTR mutations: TTR MET 30 and TTR MET 119. J Rheumatol. 1993;20:179.

6. Azevedo EP, Pereira HM, Garratt RC, Kelly JW, Foguel D, Palhano FL. Dissecting the structure, thermodynamic stability, and aggregation properties of the A25T transthyretin (A25T-TTR) variant involved in leptomeningeal amyloidosis: identifying protein partners that co-aggregate during A25T-TTR fibrillogenesis in cerebrospinal fluid. Biochemistry. 2011;50: 11070-83.

7. Saporta MA, Zaros C, Cruz MW, André C, Misrahi M, Bonaïti-Pellié C, PlantéBordeneuve V. Penetrance estimation of TTR familial amyloid polyneuropathy (type I) in Brazilian families. Eur J Neurol. 2009;16:337-41.

8. Koike H1, Misu K, Ikeda S, Ando Y, Nakazato M, Ando E, Yamamoto M, Hattori N, Sobue G. Study Group for Hereditary Neuropathy in Japan: type I (transthyretin Met30) familial amyloid polyneuropathy in Japan: early- vs late-onset form. Arch Neurol. 2002;59:1771-6. 
9. Benson MD. Liver transplantation and transthyretin amyloidosis. Muscle Nerve. 2013;47:157-62.

10. Coelho T, Maia LF, da Silva AM, Cruz MW, Planté-Bordeneuve V, Suhr OB, Conceiçao I, Schmidt HH, Trigo P, Kelly JW, Labaudinière R, Chan J, Packman J, Grogan DR. Long-term effects of tafamidis for the treatment of transthyretin familial amyloid polyneuropathy. J Neurol. 2013;260:2802-14.

11. Lopes A, Sousa A, Fonseca I, Branco M, Rodrigues C, Coelho T, Sequeiros J, Freitas P. Life paths of patients with transthyretin-related familial amyloid polyneuropathy Val30Met: a descriptive study. I Community Genet. 2018;9:93-9

12. Dohrn MF, Röcken C, De Bleecker JL, Martin JJ, Vorgerd M, Van den Bergh PY, Ferbert A, Hinderhofer K, Schröder JM, Weis J, Schulz JB, Claeys KG. Diagnostic hallmarks and pitfalls in late-onset progressive transthyretinrelated amyloid-neuropathy. J Neurol. 2013;260:3093-108.

13. Sousa MM, Du Yan S, Fernandes R, Guimaraes A, Stern D, Saraiva MJ. Familial amyloid polyneuropathy: receptor for advanced glycation end products-dependent triggering of neuronal inflammatory and apoptotic pathways. J Neurosci. 2001:21:7576-86.

14. Gonçalves NP, Vieira P, Saraiva MJ. Interleukin-1 signaling pathway as a therapeutic target in transthyretin amyloidosis. Amyloid. 2014;21:175-84.

15. Coutinho P, Martins da Silva A, Lopes Lima J, Resende Barbosa A. In: Amyloid and amyloidosis. Glenner GG, Pinho e Costa P, Falcao de Freitas A, editor. Amsterdam: Excerpta Medica; 1980. Forty years of experience with type I amyloid neuropathy. Review of 483 cases; pp. 88-98.

16. Buxbaum JN, Tagoe C, Gallo G, Walker JR, Kurian S, Salomon DR. Why are some amyloidoses systemic? Does hepatic "chaperoning at a distance" prevent cardiac deposition in a transgenic model of human senile systemic (transthyretin) amyloidosis? FASEB J. 2012;26:2283-93.

17. Sequeiros J, Sousa A, Coelho T. Sex differences and age-dependent penetrance in ATTRV-type I. In: Natvig JB, et al., editors. Amyloid and amyloidosis 1990. Dordrecht: Springer; 1991.

18. Sousa MM, do Amaral JB, Guimarães A, Saraiva MJ. Up-regulation of the extracellular matrix remodeling genes, biglycan, neutrophil gelatinaseassociated lipocalin, and matrix metalloproteinase-9 in familial amyloid polyneuropathy. FASEB J. 2005:19:124-6.

19. Singer M, Sansonetti PJ. IL-8 is a key chemokine regulating neutrophil recruitment in a new mouse model of Shigella-induced colitis. J Immunol. 2004; $173: 4197-206$.

20. Verri WA Jr, Souto FO, Vieira SM, Almeida SC, Fukada SY, Xu D, Alves-Filho JC, Cunha TM, Guerrero AT, Mattos-Guimaraes RB, Oliveira FR, Teixeira MM, Silva JS, McInnes IB, Ferreira SH, Louzada-Junior P, Liew FY, Cunha FQ. IL-33 induces neutrophil migration in rheumatoid arthritis and is a target of antiTNF therapy. Ann Rheum Dis. 2010:69:1697-703.

21. Azevedo EP, Guimarães-Costa AB, Torezani GS, Braga CA, Palhano FL, Kelly JW, Saraiva EM, Foguel D. Amyloid fibrils trigger the release of neutrophil extracellular traps (NETs), causing fibril fragmentation by NET-associated elastase. J Biol Chem. 2012;287:37206-18.

22. Ouyang W, Rutz S, Crellin NK, Valdez PA, Hymowitz SG. Regulation and functions of the IL-10 family of cytokines in inflammation and disease. Annu Rev Immunol. 2011:29:71-109.

23. Malireddi RK, Kanneganti TD. Role of type I interferons in inflammasome activation, cell death and disease during microbial infection. Front Cell Infect Microbiol. 2013;3:77.

24. Hakkim A, Fürnrohr BG, Amann K, Laube B, Abed UA, Brinkmann V, Herrmann M, Voll RE, Zychlinsky A. Impairment of neutrophil extracellular trap degradation is associated with lupus nephritis. Proc Natl Acad Sci U S A. 2010;107:9813-8.

25. Ethuin F, Delarche C, Benslama S, Gougerot-Pocidalo MA, Jacob L, CholletMartin SJ. Interleukin-12 increases interleukin 8 production and release by human polymorphonuclear neutrophils. Leukoc Biol. 2001;70:439-46.

26. Scheller J, Chalaris A, Schmidt-Arras D, Rose-John S. The pro- and antiinflammatory properties of the cytokine interleukin-6. Biochim Biophys Acta. 2011;1813:878-88

27. King SL, Hegadoren KM. Stress hormones: how do they measure up? Biol Res Nurs. 2002:4:92-103.

28. Mathey EK, Pollard JD, Armati PJ. TNF alpha, IFN gamma and IL-2 mRNA expression in CIDP sural nerve biopsies. J Neurol Sci. 1999;163(1):47-52.

29. Koike H, Tanaka F, Hashimoto R, Tomita M, Kawagashira Y, lijima M, Fujitake J, Kawanami T, Kato T, Yamamoto M, Sobue G. Natural history of transthyretin Val30Met familial amyloid polyneuropathy: analysis of lateonset cases from non-endemic areas. J Neurol Neurosurg Psychiatry. 2012 83:152-8.
30. Koike H, lijima M, Mori K, Yamamoto M, Hattori N, Watanabe H, Tanaka F, Doyu M, Sobue G. Neuropathic pain correlates with myelinated fibre loss and cytokine profile in POEMS syndrome. J Neurol Neurosurg Psychiatry. 2008:79:1171-9.

31. Kurian SM, Novais M, Whisenant T, Gelbart T, Buxbaum JN, Kelly JW, Coelho T, Salomon DR. Peripheral blood cell gene expression diagnostic for identifying symptomatic transthyretin amyloidosis patients: male and female specific signatures. Theranostics. 2016;6:1792-809.

32. Zhang $X Q, X u C F, Y u C H$, Chen WX, Li YM. Role of endoplasmic reticulum stress in the pathogenesis of nonalcoholic fatty liver disease. World J Gastroenterol. 2014;20:1768-76.

33. Urano F, Wang X, Bertolotti A, Zhang Y, Chung P, Harding HP, Ron D. Coupling of stress in the ER to activation of JNK protein kinases by transmembrane protein kinase IRE1. Science. 2000;287:664-6.

34. Liaskou E, Wilson DV, Oo YH. Innate immune cells in liver inflammation. Mediat Inflamm. 2012:949157.

35. Helk E, Bernin H, Ernst T, Ittrich $H$, Jacobs $T$, Heeren J, Tacke F, Tannich E, Lotter $\mathrm{H}$. TNFa-mediated liver destruction by kupffer cells and Ly6Chi monocytes during entamoeba histolytica infection. PLoS Pathog. 2013: e1003096.

36. Lladó L, Baliellas C, Casasnovas C, Ferrer I, Fabregat J, Ramos E, Castellote J, Torras J, Xiol X, Rafecas A. Risk of transmission of systemic transthyretin amyloidosis after domino liver transplantation. Liver Transpl. 2010;16:1386-92.

37. Reixach N, Deechongkit S, Jiang X, Kelly JW, Buxbaum JN. Tissue damage in the amyloidoses: transthyretin monomers and nonnative oligomers are the major cytotoxic species in tissue culture. Proc Natl Acad Sci U S A. 2004;101: $2817-22$.

38. Wu Y, Wu T, Wu J, Zhao L, Li Q, Varghese Z, Moorhead JF, Powis SH, Chen Y, Ruan XZ. Chronic inflammation exarcebates glucose metabolism disorders in C57BL/6J fed with high-fat diet. J Endocrinol. 2013;219:195-204

39. Oishi Y, Spann NJ, Link VM, Muse ED, Strid T, Edillor C, Kolar MJ, Matsuzaka T, Hayakawa S, Tao J, Kaikkonen MU, Carlin AF, Lam MT, Manabe I, Shimano $\mathrm{H}$, Saghatelian A, Glass CK. SREBP1 contributes to resolution of proinflammatory TLR4 signaling by reprogramming fatty acid metabolism. Cell Metab. 2017:25:412-27.

40. Cai D, Liu T. Hypothalamic inflammation: a double-edged sword to nutritional diseases. Ann N Y Acad Sci. 2011:1243:E1-39.

41. Eskan MA, Benakanakere MR, Rose BG, Zhang P, Zhao J, Stathopoulou P, Fujioka D, Kinane DF. Interleukin-1 $\beta$ modulates Proinflammatory cytokine production in human epithelial cells. Infect Immun. 2008;76:2080-9.

\section{Publisher's Note}

Springer Nature remains neutral with regard to jurisdictional claims in published maps and institutional affiliations.

Ready to submit your research? Choose BMC and benefit from:

- fast, convenient online submission

- thorough peer review by experienced researchers in your field

- rapid publication on acceptance

- support for research data, including large and complex data types

- gold Open Access which fosters wider collaboration and increased citations

- maximum visibility for your research: over $100 \mathrm{M}$ website views per year

At $\mathrm{BMC}$, research is always in progress.

Learn more biomedcentral.com/submission 